\title{
Studies on the duration of immunity induced in cattle after natural FMD infection and post vaccination with bivalent oil vaccine
}

\author{
Ehab El-Sayed, Wael Mossad, Samir Mohamed Ali, Mohamed Shawky \\ Veterinary Serum and Vaccine Research Institute, \\ P.O.Box:131, Abbasia, Cairo, Egypt. svri@idsc.gov.eg \\ Corresponding author: Ehab El-Sayed Ibrahim, email: ehabelsayed80@hotmail.com \\ Received: 08-03-2012, Accepted: 18-04-2012, Published Online: 29-07-2012 \\ doi: $10.5455 /$ vetworld.2012.603-608
}

\begin{abstract}
Aim: To detect the proper time for vaccination of infected calves after the onset of clinical signs and revaccination for previously vaccinated animals with bivalent FMD montanide ISA206 inactivated vaccine.

Materials and Methods: Twenty calves naturally infected with foot and mouth disease (FMD) showing clinical signs represented by lesions on the tongue, buccal mucosa and feet. Samples were collected from these calves including tongue epithelial and oropharyngeal fluid (OP). The causative virus was isolated from such samples through inoculation of baby mice and typed by indirect Sandwich ELISA and was confirmed in 2 tongue epithelia samples using PCR.

Results: The serum antibody titers were determined using SNT and ELISA in the sera of the 20 infected calves revealing that the infected farms should be vaccinated with inactivated bivalent FMD vaccine for (type $\mathrm{O}$ and A) Adjuvanted with montanide ISA206 after 32 weeks from the appearance of clinical signs. In addition the FMD immune status was monitored in 2 farms in EL-Fayoum and El-Sharkia Governorates where 50 calves in each farm were vaccinated with the bivalent FMD inactivated vaccine adjuvaned with montanide ISA206 and serum samples were collected monthly from these animals to determine their immune status using SNT and ELISA. The obtained results showed that vaccinated calves with the bivalent FMD montanide ISA206 inactivated vaccine should be revaccinated after 36 weeks post vaccination.

Conclusions: naturally infected calves should be vaccinated on the 32 weeks post infection while vaccinated calves should be revaccinated on the 36 weeks post vaccination

Key words: bivalent montanide ISA206 vaccine, ELISA, Foot and Mouth disease, infection, SNT, vaccination
\end{abstract}

To cite this article: El-Sayed E, Mossad W, Ali SM, Shawky M (2012) Studies on the duration of immunity induced in cattle after natural FMD infection and post vaccination with bivalent oil vaccine, Vet World, 5(10): 603-608, doi: 10.5455/vetworld.2012.603-608

\section{I ntroduction}

Foot and Mouth disease (FMD) is a highly infectious disease of ungulates primarily cattle, sheep, goats and pigs. It also affects wild animals such as buffaloes and deer [1]. Foot-and-mouth disease virus (FMDV) is the etiologic agent of one of the most devastating diseases that can affect cloven-hoofed livestock. Infection with FMDV causes an acute disease that spreads very rapidly and is characterized by fever, lameness and vesicular lesions on the feet, tongue, snout and teats, with high morbidity but low mortality [2].

There are seven types of FMD virus (FMDV) have been identified as; $\mathrm{O}, \mathrm{A}, \mathrm{C}, \mathrm{SAT}_{1}, \mathrm{SAT}_{2}, \mathrm{SAT}_{3}$ and Asia1 [3]. Cattle infected with FMDV show rapid rise in serum antibody, $\operatorname{IgG}_{1}$ could be detectable at 7-10 days post-infection and is highly serotype-specific. Serum antibody level's peak can be detected around 28 days and remain at protective titers [4]. The duration of antibody response in cattle experimentally infected with FMDV lasted for a period of 40 weeks. The maximum antibody titer was reached at 10 weeks post infection followed by steady reduction to the $4^{\text {th }}$ month post infection [5]. Neutralizing antibodies persisted for 18 months in convalescent cattle experimentally infected with FMDV. The serum neutralizing antibodies rose to high titers within 7 to 10 days after infection of cattle with type 'O' FMD virus. Such level remained high for 4 months; while the virus could be isolated from oesophageal pharyngeal fluid (OP) up to 4 weeks post inoculation [6].

Montanide ISA206 oil adjuvant quadrivalent FMD vaccine elicited a better immune response at any time than aluminum hydroxide gel vaccine, and this response was developed quicker. The animals maintained their neutralizing antibody titers at $>3 \log _{10}$ 
Studies on the duration of immunity induced in cattle after natural FMD infection and post vaccination with bivalent oil vaccine

Table-1. Primers used in the study.

\begin{tabular}{lllccc}
\hline Primers & Orientation & Sequence (5'- $\left.\mathbf{3}^{\prime}\right)$ & Serotype specific & Genomic location & bp \\
\hline 1 & Forward & TACCAAATTACACACGGGAA & A & $1 \mathrm{D}$ & 800 \\
2 & Reverse & GACATGTCCTCCTGCATCTG & A & 1D & 800 \\
3 & Forward & AGCTTGTACCAGGGTTTGC & O & 1D & 402 \\
4 & Reverse & GCTGCCTACCTCCTTCAA & O & 402 \\
\hline
\end{tabular}

for the duration of the trial (90 days) [7]. The mean protective serum antibody titers against FMD in calves vaccinated with double oil emulsion (Montanide ISA 206) evaluated by ELISA and SNT was started at $3^{\text {rd }}$ week post vaccination (WPV) reached the highest level at the $10^{\text {th }} \mathrm{WPV}$ and continued with the protective level till the $32 \mathrm{WPV}$ then started to decline under the protective level for both FMD virus types $\mathrm{O}$ and $\mathrm{A}$ [8].

\section{Materials and Methods}

Animals:

Naturally infected calves: Twenty naturally infected male local breed calves of 6 month old were subjected to the present studies.

Vaccinated calves: Fifty calves in each of 2 farms in El-Fayoum and EL-Sharkia were clinically healthy and free from antibodies against $\mathrm{O}_{1} / 93$ and A/Egypt/2006 foot and mouth disease virus as proved by serum neutralization test (SNT) and Enzyme linked Immunosorbant Assay (ELISA). These animals were vaccinated with the local inactivated bivalent oil FMD vaccine with a dose of $2 \mathrm{ml}$ injected subcutaneously in each calf.

Suckling baby mice: Sixty suckling Swiss Albino mice of 2-3 days old were used for isolation and titration of FMD virus through the inoculation intraperitoneal (I/P). They were supplied by Veterinary Serum and Vaccine Research Institute (VSVRI) - Abassia- Cairo.

FMD virus: Locally isolated foot and mouth disease virus (FMDV/O /93/Aga), (FMDV/A/Egypt/2006) of cattle origin typed and sub-typed at the FMD Department Veterinary Serum and Vaccine Research Institute, Abbasia, Cairo and confirmed by world reference Laboratories, Pirbright, United Kingdom. The virus stock was stored at $-70^{\circ} \mathrm{C}$. These viruses were adapted on BHK cell culture and used in serum neutralization test and preparation of virus antigen for ELISA.

Vaccine: Local produced inactivated bivalent FMD vaccine for type $\left(\mathrm{O}_{1} / 93 / \mathrm{Aga}\right)$ and type (A/Egypt/2006) adjuvanted with Montanide ISA 206 oil was supplied by Veterinary Serum and Vaccine Research Institute to be used for vaccination of calves in the 2 mentioned farms.

\section{Samples:}

Serum samples: Serum samples were collected from 20 naturally infected calves from different governorates at the time of clinical signs appearance (zero time) then every 4 weeks for 32 weeks.

Serum samples were collected from 100 vaccinated calves ( 50 calves in each of 2 farms) before vaccination and every 4 weeks for 36 weeks post vaccination.

Samples of virus isolation: Oesophageal Pharyngeal fluid (OP) using probing sampling cup and tongue epithelium (TE) samples were collected from 20 naturally infected calves showing the characteristic signs of FMD.

Cell culture: Baby Hamster kidney cell line (BHK21) Clone 13 maintained in FMD Department, Abbasia, Cairo using Eagl's medium with 8-10\% sterile bovine serum as described by [9] was used for application of serum neutralization test.

Serum neutralization test ( SNT): It was performed using the micro titer technique as described by [10].

Indirect enzyme linked immune sorbent assay (ELISA): ELISA and its reagents were prepared according to [11] used to follow up the immune response in animals.

I ndirect Sandwich ELI SA: Indirect Sandwich ELISA and its reagents were prepared according to [12] used for typing the isolated virus.

PCR: It was applied on the tongue epithelial and OP using 2 specific primers against A, O to confirm typing of the 2 infected calves according to [13] using the demonstrated primers in Table-1.

\section{Results and Discussion}

The clinical signs described in naturally infected calves (Table-2) included either the lesions on tongue epithelial or on buccal mucosa and feet. The lesions vary from erosion, vesicles and ulceration. These signs appear to be characteristic for FMD as stated by [14]; [7] and [15].

Trials of virus isolation (Table-3) from the 
Studies on the duration of immunity induced in cattle after natural FMD infection and post vaccination with bivalent oil vaccine

Table-2. FMD lesions in naturally infected cattle

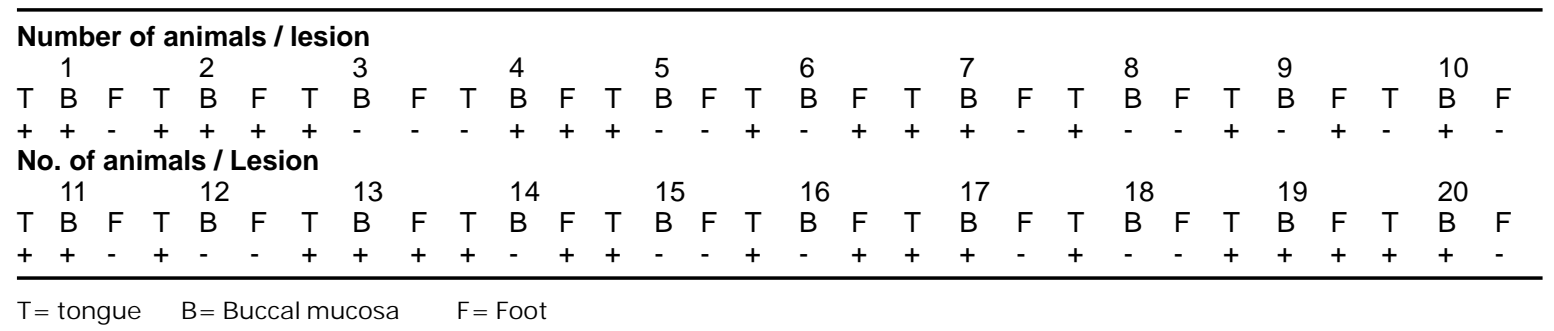

Table-3. I solation and identification of FMDV from different samples by baby mice inoculation and ELISA

\begin{tabular}{|c|c|c|c|c|}
\hline \multirow{3}{*}{$\begin{array}{l}\text { No. of } \\
\text { animals }\end{array}$} & \multicolumn{4}{|c|}{ Virus isolation and identification } \\
\hline & & \multicolumn{2}{|c|}{ OP** } \\
\hline & Baby mice & ELISA*** & Baby mice & ELISA \\
\hline 1 & + & A & + & A \\
\hline 2 & + & 0 & + & 0 \\
\hline 3 & + & $\mathrm{O}$ & + & $\mathrm{O}$ \\
\hline 4 & \multicolumn{2}{|c|}{ No lesion } & + & $\mathrm{O}$ \\
\hline 5 & + & $A$ & + & $A$ \\
\hline 6 & + & 0 & + & 0 \\
\hline 7 & + & A & + & A \\
\hline 8 & + & $\mathrm{O}$ & + & 0 \\
\hline 9 & + & 0 & + & $\mathrm{O}$ \\
\hline 10 & \multicolumn{2}{|c|}{ No lesion } & + & A \\
\hline 11 & + & $\mathrm{O}$ & + & 0 \\
\hline 12 & + & 0 & + & 0 \\
\hline 13 & + & $\mathrm{O}$ & + & $\mathrm{O}$ \\
\hline 14 & + & $\mathrm{O}$ & + & 0 \\
\hline 15 & + & 0 & + & $\mathrm{O}$ \\
\hline 16 & + & $\mathrm{O}$ & + & $\mathrm{O}$ \\
\hline 17 & + & $A$ & + & A \\
\hline 18 & + & 0 & + & $\mathrm{O}$ \\
\hline 19 & + & $\mathrm{O}$ & + & 0 \\
\hline 20 & + & $\mathrm{O}$ & + & $\mathrm{O}$ \\
\hline
\end{tabular}

Table-4. Mean FMD antibody titers in the naturally infected calves using SNT and ELISA

\begin{tabular}{|c|c|c|c|c|}
\hline \multirow[t]{2}{*}{ WPI* } & \multicolumn{4}{|c|}{$\begin{array}{l}\text { Mean antibody titers (Log10/mI) } \\
\text { SNT }\end{array}$} \\
\hline & Type A & Type 0 & Type A & Type 0 \\
\hline 1 & 0.9 & 1.02 & 1.15 & 1.32 \\
\hline 4 & 1.55 & 1.77 & 1.65 & 2.07 \\
\hline 8 & 1.85 & 1.9 & 2 & 2.15 \\
\hline 12 & 1.95 & 2.22 & 2.3 & 2.52 \\
\hline 16 & 2.35 & 2.45 & 2.5 & 2.7 \\
\hline 20 & 2 & 2.1 & 2.2 & 2.35 \\
\hline 24 & 1.82 & 1.9 & 2 & 2.1 \\
\hline 28 & 1.71 & 1.8 & 1.95 & 2 \\
\hline 32 & 1.6 & 1.6 & 1.9 & 1.92 \\
\hline 36 & 1.4 & 1.5 & 1.7 & 1.84 \\
\hline
\end{tabular}

$* \mathrm{WPI}=$ week post infection collected tongue epithelium; and oesopharyngeal fluid through the intrapretonial inoculation of baby mice revealed positive results represented by paralysis of the hind limbs of all inoculated mice in agreement with [16] who isolated the FMDV from infected animals in baby mice concluded that mice are suitable models to study the pathogenicity of FMD.

Identification and serotyping of isolated FMDV from collected samples of naturally infected calves by Indirect Sandwich ELISA revealed that 5 out of 20 infected calves were typed as FMDV serotype A while 15 isolates were typed serotype $\mathrm{O}$ (Table-3). These results were confirmed using PCR on 2 samples as examples ( 1 sample type $\mathrm{O}$ and 1 sample type $\mathrm{A}$ ) as shown in photo (1\&2). In this respect the use of Indirect Sandwich ELISA and PCR for identification and typing of FMDV was agreed with [12,17-22].

Studying the immune status in naturally infected calves as evaluated by SNT and ELISA (Table-4\& Fig. $1 \& 2$ ) showed that the peak of circulating FMD type A and $\mathrm{O}$ antibodies were recorded on the 16 weeks post infection. Similar findings were obtained by [23] recording peaks of FMD antibodies in infected cattle between 15-16 weeks post infection. Also [24] stated that the clinical signs decline with the appearance of circulating FMD specific antibody at around 4 to 5 days post infection. The titer of these antibodies remained within the protective level $\left(1.5 \log _{10} / \mathrm{ml}\right.$ for SNT and $1.9 \log _{10}$ for ELISA) as reported by [17] up to 36 weeks for type $\mathrm{O}$ and 32 weeks for type $\mathrm{A}$.

Vaccination of calves with the locally produced bivalent FMD vaccine adjuvanted with Montanid ISA 206 induced higher antibody titers than the recommended protective level $\left(1.5 \log _{10}\right.$ for SNT and $1.9 \log _{10}$ for ELISA) for both of type $\mathrm{A}$ and $\mathrm{O}$ as estimated by SNT and ELISA (Table-5 and Fig.3\&4) on the $4^{\text {th }}$ week post vaccination to record peak titers by the 12 week post vaccination for both types. These antibody titers remained within the protective level up to 36 weeks post vaccination in the 2 farms under studies.

These results agree with those of $[7,25,26]$ who indicated that Montanide ISA 206 achieving early 
Studies on the duration of immunity induced in cattle after natural FMD infection and post vaccination with bivalent oil vaccine

Table-5. Mean FMD serum neutralizing antibody titers in vaccinated calves with the bivalent oil FMD

\begin{tabular}{|c|c|c|c|c|c|c|c|c|}
\hline \multirow[t]{4}{*}{ WPV* } & \multicolumn{8}{|c|}{ Mean FMD serum antibody titers $(\log 10 / \mathrm{ml}) /$ WPV* in } \\
\hline & \multirow{2}{*}{\multicolumn{2}{|c|}{ SNT Farm-1 }} & \multirow{2}{*}{\multicolumn{2}{|c|}{$\begin{array}{l}\text { ayoum) } \\
\text { ELISA }\end{array}$}} & \multirow{2}{*}{\multicolumn{2}{|c|}{ SNT ${ }^{\text {Farm-2 }}$}} & harkia) & \\
\hline & & & & & & & \multicolumn{2}{|c|}{ ELISA } \\
\hline & TypeA & TypeO & TypeA & Type 0 & TypeA & TypeO & TypeA & TypeO \\
\hline 0 & 0.132 & 0.175 & 0.212 & 0.51 & 0.05 & 0.122 & 0.39 & 0.31 \\
\hline 4 & 1.782 & 1.9 & 1.926 & 2.13 & 1.65 & 1.779 & 1.84 & 1.99 \\
\hline 8 & 2.232 & 2.3 & 2.542 & 2.59 & 2.175 & 2.241 & 2.49 & 2.62 \\
\hline 12 & 2.534 & 2.662 & 2.823 & 2.84 & 2.212 & 2.139 & 2.51 & 2.4 \\
\hline 16 & 2.316 & 2.437 & 2.51 & 2.67 & 2.15 & 2.125 & 2.44 & 2.56 \\
\hline 20 & 2 & 2.2 & 2.4 & 2.5 & 1.95 & 1.99 & 2.31 & 2.44 \\
\hline 24 & 1.946 & 2.087 & 2.25 & 2.38 & 1.863 & 1.881 & 2.19 & 2.27 \\
\hline 28 & 1.89 & 1.962 & 2.18 & 2.28 & 1.913 & 1.911 & 2.11 & 2.14 \\
\hline 32 & 1.746 & 1.787 & 2 & 2.1 & 1.763 & 1.761 & 2.09 & 2.03 \\
\hline 36 & 1.65 & 1.637 & 1.98 & 1.95 & 1.613 & 1.635 & 1.95 & 1.99 \\
\hline 40 & 1.482 & 1.487 & 1.76 & 1.69 & 1.45 & 1.476 & 1.52 & 1.62 \\
\hline
\end{tabular}

$* \mathrm{WPV}=$ week post vaccination N.B: SNT titer was expressed by log 10
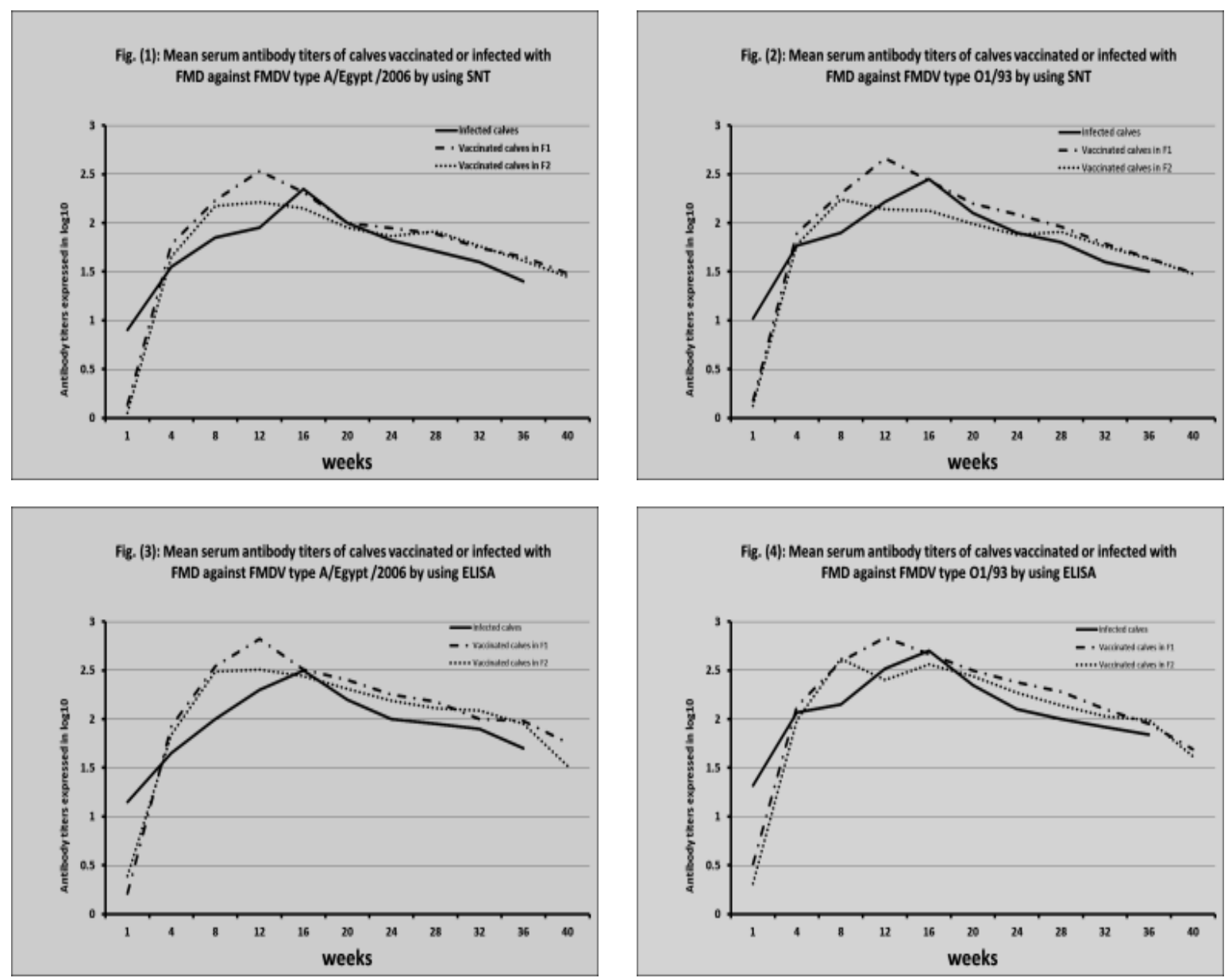


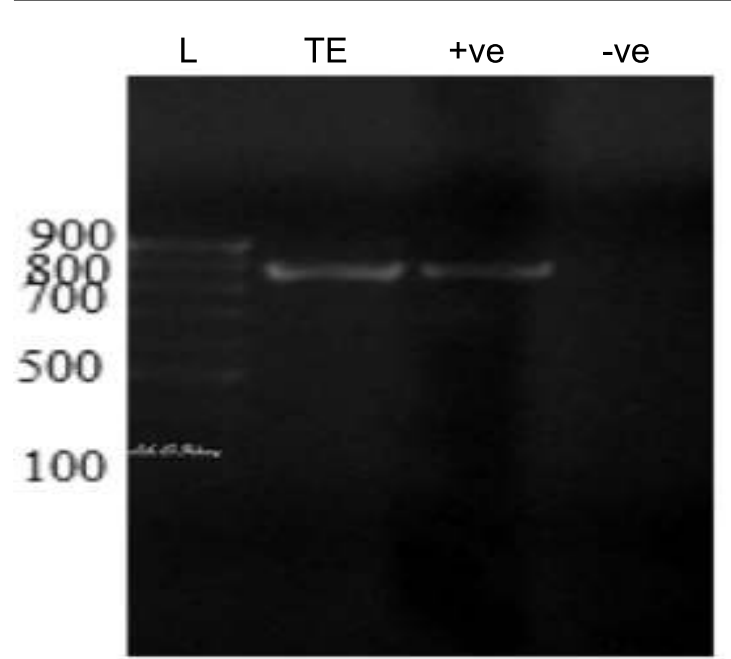

Photo-1. PCR for TE and OP positive band in 800bp (serotype A) L: Ladder, TE: Tongue epithelial of sample NO. 1, +ve: positive control, -ve : negative sample

protective titers and longer lasting immunity. Also [27] found that the immune response of vaccinated goats with DOE Montanide ISA 206 vaccines persisted for 36 weeks post vaccination. In addition, [28] suggested that high potency vaccines adjuvanted with Montanide ISA 206 can promote long lasting immunity.

The obtained results showed that the protective titers of FMD antibodies were persisted up to 32 weeks post infection in naturally infected calves and up to 36 weeks in calves vaccinated with the Montanid ISA 206 oil bivalent FMD vaccine.

\section{Conclusion}

It could be concluded that naturally infected calves should be vaccinated on the 32 weeks post infection while vaccinated calves should be revaccinated on the 36 weeks post vaccination to avoid the decline of the protective immune levels to the non-protective values.

\section{Author's contribution}

Ehab El-Sayed Ibrahim vaccinated the animals with the new bivalent FMD oil vaccine and follow up the post vaccinal reaction and applied the SNT and ELISA on the serum of vaccinated animals. Wael Mossad searched naturally infected animals and follow up the antibody titers by SNT and ELISA on the serum of infected animals. Samir Mohamed analysed the Data and tabulated. Mohamed Shawky applied PCR technique, evaluate the data and supervise on write the research. All authors read and approved the final manuscript.

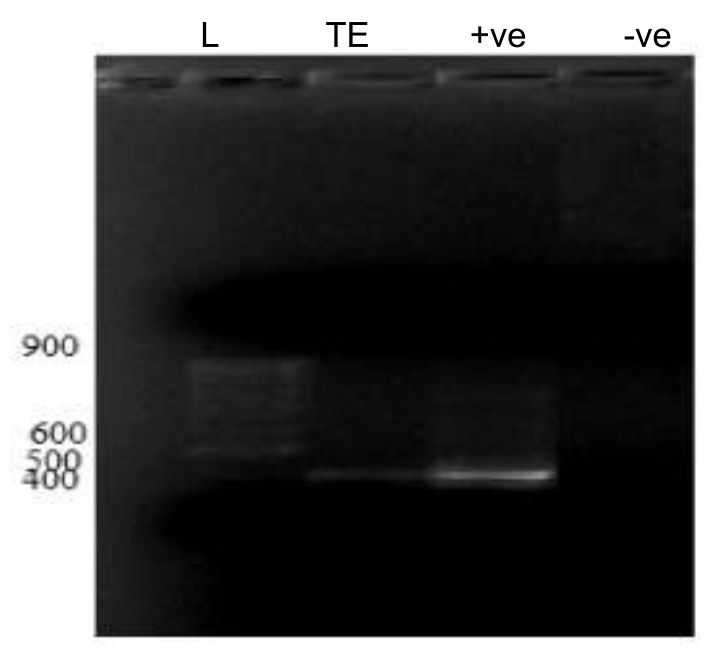

Photo-2. PCR for TE and OP positive band in 402bp (serotype O) L: Ladder, TE: Tongue epithelial of sample NO. 2, +ve: positive control, -ve : negative sample

\section{Acknow ledgements}

Authors are thankful to Prof. Dr. Seham Abd ELRashid Director of VSVRI, Prof. Dr. Sayed Zedan Deputy of VSVRI and all members of FMD department specially Prof. Dr. Magdy Abd El-Aty head of FMD department, VSVRI.

\section{Competing interests}

Authors declares that they have no competing interests.

\section{References}

1. Donaldson A.I. and Alexanderson S. (2002). Predicting the spread of FMD by airborne virus. Rev. Sci. Tech., Dec.; 21(3): 569-575.

2. Grubman, M.J. and Baxt, B., (2004). Foot-and-mouth disease. Clin. Microbiol. Rev. 17, 465-493.

3. Franki, R.I.B., Fauquet, C.M., Knudson, D.L. and Brown, F. (1991). Classification and nomenclature of viruses. $5^{\text {th }}$ Report of Int. Comm. on taxonomy of viruses, suppl. 2.

4. Salt B.C. (1993). The carrier state in FMD, an immunological review. Br. Vet. J., May-June.; 149(3): 207-23.

5. Moussa, A.A.M., Ibrahim, M.H. and Hussein, K. (1976).Preliminary study on antibody response of cattle after experimental infection with FMDV. Proc. Of the $13^{\text {th }}$ Arab Vet. Conger., Cairo, 13-18 February.

6. Matsumato, M., McKercher, P.D. and Nusbaum, K.E (1978).Secretory antibody response in cattle infected with FMDV.Am. J. Vet. Res., 39 (7): 1081- 1087.

7. Patil, P.K., Bayry, J., Ramakrishna, C., Hugar, B., Misra, L.D., Natarajan, C. (2002).Immune response of goats against FMD quadrivalent vaccine: comparison of double oil emulsion and aluminum 
hydroxide gel vaccine in eliciting immunity. Vaccine, 20: 2781-2789.

8. Gamil, M. A (2010). Studies on the immune response of calves vaccinated inactivated bivalent FMD virus vaccine type $\mathrm{O} 1$ and A Egypt 2006. M.V.Sc Thesis in Veterinary Science (virology). Benha University.

9. Huang Xuan, Yong Li, Hui Fang and Congyi Zheng (2011). Establishment of persistent infection with foot and mouth disease virus in BHK-21 cells. Virology Journal, 8:169.

10. Ferreira M. E. V. (1976). Prubade microneutralization poraestudies de anticueropos de la fibre aftosa. $13^{\text {th }}$ Centropanamericano Fiebre Aftosa, (21/22): 17-24.

11. Ferris, N. P., Kitching, R. P., Oxtoby, J. M., Philpot, R.M. and Rendle, R. (1990). Use of inactivated footand-mouth disease virus antigen in liquid-phase blocking ELISA. Journal of Virological Methods, 29: 33-41.

12. Alonso Albino, Mauricio A. Martins, Maria da Penha D. Gomes, Rossana Allende and Magnus S. Söndahl (1992).Foot-and-mouth disease virus typing by complement fixation and enzyme-linked immunosorbent assay using monovalent and polyvalent antisera. J Vet Diagn Invest 4:249-253.

13. Le, V.P., Lee, K.N., Nguyen, T., Kim, S.M., Cho, I.S., Dong, V.Q., Dinh, D.K., Park, J.H., (2011). Development of one-step multiplex RT-PCR method for simultaneous detection and differentiation of footand-mouth disease virus serotypes $\mathrm{O}, \mathrm{A}$, and Asia 1 circulating in Vietnam. J. Virol. Methods (Epub ahead of print).

14. Radostits, O.M.; Blood, D.C. and Goy, C.C. (1995).Veterinary Medicine, P. 965-973. Educational low priced blooks scheme, Funded by the British Government, 8th Ed.

15. Orsel K., A. Bouma, A. Dekker, J.A. Stegeman, M.C.M. de Jong (2009). Foot and mouth disease virus transmission during the incubation period of the disease in piglets, lambs, calves, and dairy cows.

16. Salguero, F.J., Sanchez-Martin, M.A., Diaz-San Segundo, F., de Avila, A., Sevilla, N. (2005).Footand-mouth disease virus (FMDV) causes an acute disease that can be lethal for adult laboratory mice. Centro de Investigacion en Sanidad Animal, INIA, 28130 Valdeolmos, Madrid, Spain. Virology. Feb 5; 332(1): 384-96.

17. OIE (2010).Foot and mouth disease, Chapter 2.1.1. In manual of standards for diagnostic tests and vaccine, $4^{\text {th }}$ Ed. 2000, Paris, 77-92.
18. Kris De clercq (2002). Overview of FMD diagnostic techniques. FMD, Control Strategies International Symposium,2-5 June, France. Abstract book, 107.

19. Marquardt,O.; Straub, O.C. and Haas, B. (1995) Detection of foot-and-mouth disease virus, independent of type within 24 hours by the polymerase chain reaction applied to nasal swabs Tierarztliche Umschau, 50(5):344-346.

20. Oleksiewicz, M. B., Donaldson, A. I. \& Alexandersen, S. (2001). Development of a novel real-time RT-PCR assay for quantitation of foot-andmouth disease virus in diverse porcine tissues. $J$. Virol. Methods. 92, 23-35.

21. Le V. P., Kwang-Nyeong Le, Tung Nguyen, Su-Mi Kim, In-Soo Cho, Dinh Duy Khang, Nguyen Ba Hien, Dong Van Quyen, and Jong-Hyeon Park (2012).A rapid molecular strategy for early detection and characterization of Vietnamese foot-and-mouth disease virus serotypes $\mathrm{O}, \mathrm{A}$, and Asia 1. Journal of Virological Methods 180 (2012) 1-6.

22. Ghoneim, N.H., Abdel- Karim, A.K.M., Laila ElShehawy and Abdel- Moein K. A. (2010). FMD in animals in Sharkia governorate, Egypt. Trans. \& Emerg. Dis. 1-4.

23. Mossad, W.G. (2007). "Studies on Foot and Mouth disease virus excretion and transmission from experimentally infected cattle and sheep to their contact animal". M.V.Sc. Thesis submitted to Faculty of Vet. Med, Suez Canal University.

24. Declerq K. (2002). Overview on foot and mouth disease diagnostic techniques. In FMD control strategies, symposium proceedings, 2-5 June 2002, Lyon, France: $345-351$.

25. Bayry, J.; Prabhudas, K. and Suryanarayana, V.V.(1999).Preparation of ISCOMs with urea solubilised recombinant FMDV protein. Vaccine, May14;17(19):2333-4

26. Barnard, A.L.; Arriens, A.; Cox, S.; Barnett, P.; Kristensen, B.;Summerfield, A. and, McCullough, K.C(2005).Immune response characteristics following emergency vaccination of pigs against footand-mouth disease. Vaccine. Jan 11;23(8):1037-47.

27. Fathia, A.M. (2003). Vaccination of goats with FMD vaccines. MVSc Thesis, University of Alexandria.

28. Cox, S.J.; Aggarwal, N.;Statham, R.J. and Barnett P.V.(2003).Longevity of antibody and cytokine responses following vaccination with high potency emergency FMD vaccines. Vaccine, Mar 28;21(1314):1336-47. 